\title{
Efeito do armazenamento a frio e desidratação sobre o enraizamento de estacas herbáceas de Dendranthema grandiflora ${ }^{(1)}$
}

\author{
NATALIA TEIXEIRA SCHWAB(2), MAURICIO NEUHAUS(3), ROGÉRIO ANTÔNIO BELLÉ(4), \\ FERNANDA ALICE ANTONELLO LONDERO BACKES(5), MARCIA XAVIER PEITER(6)
}

\begin{abstract}
RESUMO
O experimento foi desenvolvido no setor de floricultura do Departamento de Fitotecnia da Universidade Federal de Santa Maria - Santa Maria, RS, no período de novembro a dezembro de 2007 e teve como objetivo avaliar o efeito do armazenamento a frio e da desidratação sobre o enraizamento de estacas herbáceas de Dendranthema grandiflora, cultivares 'Satllion' e ‘Toon Hermans', tratadas com Ácido Indol Butírico (AIB) 0,1\%. As estacas herbáceas foram coletadas no matrizeiro localizado no Setor de Floricultura, apresentando $6 \mathrm{~cm}$ de comprimento final, e foram então armazenadas a frio por diferentes períodos de tempo $(0 ; 7 ; 14$ e 21 dias), sendo que cada tratamento constou de 20 repetições. As estacas depois de tratadas com AIB 0,1\% foram pesadas antes e após o armazenamento para obter o percentual de perda de umidade e, logo após, foram plantadas em bandejas de enraizamento contendo casca de arroz carbonizada e colocadas em estufa onde permaneceram 15 dias até sua avaliação. Para a avaliação do efeito da estocagem a frio e desidratação, foram realizadas as seguintes medições: comprimento total das raízes nas estacas e número de raízes por estaca.

Os resultados obtidos neste trabalho mostraram que certo nível de frio é favorável ao enraizamento, porém este efeito deve ser observado quanto a cultivar e ao tempo de exposição das estacas às baixas temperaturas. Além disso, foi possível observar que a capacidade de formação e crescimento das raízes pelas estacas é um caráter varietal, o que determina um melhor desempenho das plantas.
\end{abstract}

Palavras-chave: Crisântemo, Estocagem a Frio, Propagação Vegetativa.

ABSTRACT

Effects of cold storage and dehydration on rooting of herbaceous cuttings of Dendranthema grandiflora

The experiment was developed at the Setor de Floricultura in the Departmento de Fitotecnia at Universidade Federal de Santa Maria - Santa Maria, RS, in the period from November to December 2007, and aimed at evaluating the effects of cold storage and dehydration on rooting of herbaceous cuttings of Dendranthema grandiflora, more specifically of 'Satllion' and 'Toon Hermans' cultivars, treated with indolebutyric acid (IBA) $0,1 \%$. The herbaceous cuttings were collected from the nursery located at the Setor de Floricultura, presenting $6 \mathrm{~cm}$ of final length, and were then stored in cold for different periods of time (0;7;14 and 21 days), each treatment consisting of 20 repetitions. After being treated with IBA $0,1 \%$, the cuttings were weighted after and before storage to obtain the percentage of loss of humidity and, soon after that, planted in rooting trays which contained carbonized rice skin and were then conserved in greenhouse for 15 days, until their evaluation. For the evaluation of effects of cold storage and dehydration, the following measurements were carried out: total length of roots on the cuttings and number of roots by cutting. The results obtained in this work showed that a certain level of cold is favorable to rooting; however, this effect must be observed concerning the cultivar and the time of exposition of cuttings to low temperatures. Besides that, we could observe that the capacity of formation and growth of roots by cutting is a varietal character, which determines a better performance of plants.

Keywords: chrysantemum, cold Storage, vegetative propagation.

\section{INTRODUÇ̃̃O}

A floricultura é um setor altamente competitivo que exige a utilização de tecnologias avançadas, profundo conhecimento técnico e um sistema eficiente de produção, distribuição e comercialização (MATSUNAGA, 1995).

No Brasil, segundo JUNQUEIRA E PEETZ (2004), a principal espécie produzida no setor de floricultura é o crisântemo (Dendranthema grandiflora), devido à cultura apresentar flores com grande diversidade de formas e cores, precisão de resposta de indução floral ao fotoperíodo e, principalmente, devido à longevidade de suas inflorescências (TOLOTTI, 2001). Por ser uma cultura de bom valor comercial, de alta tecnologia de produção e exigente em fotoperíodo, sua produção é conduzida, geralmente, em ambiente protegido, de maneira a fornecer flores ao mercado, durante o ano todo (FURLAN, 1996).

As mudas comerciais de crisântemo, utilizadas para a produção de flores de corte e de vaso, são produzidas exclusivamente em São Paulo, por empresas especializadas no ramo. Depois de colhidas, podem ser armazenadas a frio $\left(5\right.$ a $\left.8{ }^{\circ} \mathrm{C}\right)$ por até quatrosemanas, sendo que seu trans-

\footnotetext{
(1)Recebido em 10 de maio de 2013 e aceito para publicação em 30 junho de 2013.

${ }^{(2)}$ Eng. Agrônoma, doutoranda em Produção Vegetal na Faculdade de Ciências Agrárias e Veterinárias FCAV - UNESP, Campus de Jaboticabal, SP. CEP: 14884-900. Email: mfbdurigan@yahoo.com.br

${ }^{(3)}$ Prof. Dr. do Depto de Tecnologia da FCAV/UNESP, Campus de Jaboticabal, SP. Email: benhur@fcav.unesp.br.

${ }^{(4)}$ Profa. Dra. do Depto de Biologia da FCAV/UNESP, Campus de Jaboticabal, SP.

${ }^{(5)}$ Profa. Dra. Faculdade Moura Lacerda, Ribeirão Preto. Email: cmattiuz@gmail.com
} 
porte até os produtores mais distantes do território nacional pode demorar até uma semana. Assim, durante todo esse período que engloba o armazenamento e transporte, a muda passa por um processo de desidratação, de acordo com as condições do manuseio, e também sofre a ação do frio, podendo chegar ao produtor em situação de alta desidratação, o que compromete a eficácia do processo de enraizamento, reduzindo, então, sua qualidade.

Os objetivos do trabalho foram simular os procedimentos de armazenagem de mudas e escalonamento de produção, que são comuns nas grandes empresas produtoras de estacas de crisântemo, e avaliar as respostas quanto ao efeito do tempo de armazenamento a frio sobre a desidratação e enraizamento das mudas, além das possíveis interferências varietais sobre o crescimento e desenvolvimento de raízes nas estacas.

\section{MATERIAL E MÉTODOS}

O experimento foi instalado em Casa de vegetação no setor de floricultura do Departamento de Fitotecnia da Universidade Federal de Santa Maria, Santa Maria - RS, e organizado na forma bifatorial $(4 \times 2)$ no delineamento inteiramente casualizado, com 20 repetições. O fator tempo constituiu-se de quatro períodos de armazenamento em câmara fria (sem frio ou testemunha; 7 dias; 14 dias e 21 dias de armazenamento a frio) e o fator cultivar foi composto por duas cultivares ('Stallion' e 'Toon Hermans'). Este experimento foi realizado durante os meses de novembro e dezembro de 2007.

As estacas foram tratadas com AIB, identificadas e pesadas, sendo posteriormente embaladas em sacos plásticos perfurados, contendo 20 estacas cada, e acondicionadas em câmara fria. As estacas que constituíam a testemunha foram colhidas, homogeneizadas e tratadas com AIB alguns minutos antes do plantio.

A temperatura de armazenamento das estacas foi de $7^{\circ} \mathrm{C}\left( \pm 1^{\circ} \mathrm{C}\right)$, onde estas permaneceram por 7,14 e 21 dias em armazenamento a frio, que constituíam os tratamentos, além da testemunha. Logo após cada um dos períodos de armazenagem, as estacas foram pesadas novamente para a verificação da perda de umidade em comparação a primeira pesagem. Em seguida, as estacas tratadas foram plantadas em bandejas contendo casca de arroz carbonizada e acondicionadas em Casa de vegetação.

Durante o período experimental, as estacas foram mantidas sob regime de dias longos. A variação de temperatura foi controlada por um termômetro posicionado junto às mudas que indicou variação de $17,5^{\circ} \mathrm{C}$ a $31,6^{\circ} \mathrm{C}$, para o período compreendido entre 10 a 25 de dezembro de 2007 (período de enraizamento) e, as irrigações foram feitas sempre que necessário, ao longo do dia.

Realizaram-se as avaliações 15 dias após a data de plantio, quando se observou o número e comprimento de raízes formadas.

A análise estatística foi realizada através do software ESTAT 2.0, seguindo o modelo de análise para o delineamento inteiramente casualizado bifatorial, constando inicialmente da análise de variância e teste F. Quando o efeito mostrou-se significativo, foi aplicado aos resultados o teste de Tukey em nível de 5\% de probabilidade de erro, além da análise de regressão para os fatores quantitativos. Também foi calculado o ponto de máxima das curvas referentes ao comprimento e número de raízes através da equação matemática $X^{*}=-b / 2 c$.

\section{RESULTADOS E DISCUSSÃO}

Os valores médios referentes ao comprimento de raízes e número de raízes por estaca em crisântemo sob ação do frio são apresentados na Tabela 1. Observa-se que não houve diferença significativa entre o controle e o tempo de armazenamento a frio de 7 e 14 dias,e e que estes tratamentos apresentaram maior comprimento de raízes das estacas de crisântemo em relação às estacas que permaneceram por 21 dias armazenados a $7^{\circ} \mathrm{C}\left( \pm 1^{\circ} \mathrm{C}\right)$.

Em relação ao número de raízes por estaca, verifica-se que o tempo de armazenamento não exerceu influência sobre esta variável (Tabela 1).

Tabela 1. Valores médios do comprimento de raízes e número de raízes por estaca em função do armazenamento a frio de estacas de crisântemo. Santa Maria, 2009.

Table 1. Mean values of root length and number of roots per cutting due cold storage of chrysanthemum cuttings. Santa Maria, 2009.

\begin{tabular}{ccc}
\hline Armazenamento a frio (dias) & Comprimento de raízes $(\mathrm{cm})$ & Número de raízes por estaca \\
\hline Testemunha & $17,63 \mathrm{a}^{*}$ & $17,00 \mathrm{a}$ \\
7 & $22,97 \mathrm{a}$ & $18,22 \mathrm{a}$ \\
14 & $25,82 \mathrm{a}$ & $19,07 \mathrm{a}$ \\
21 & $16,33 \mathrm{~b}$ & $16,15 \mathrm{a}$
\end{tabular}

* Médias da mesma coluna seguida de uma mesma letra não diferem entre si ao nível de $5 \%$ de probabilidade pelo teste de Tukey.

Ressalta-se que as estacas de ambas as cultivares sofreram desidratação durante o período de armazenamento a frio, já que o ambiente refrigerado utilizado não apresentava dispositivos de controle de umidade. Para a cultivar 'Stallion' a perda de água ocorreu de forma um pouco mais intensa do que para a cultivar 'Toon Hermans', provavelmente devido a aspectos relacionados a características da epiderme da folha, tais como:, epessura da cutícula, número de estômatos por área, densidade de tricomas, entre outros, que podem variar entre as cultivares. Sendo assim, durante o 
período de tempo de 7; 14 e 21 dias de armazenamento a frio, a cultivar 'Stallion' apresentou um percentual de desidratação de $7,12 \%, 11,83 \%$ e $22,17 \%$, respectivamente. Já a cultivar 'Toon Hermans' mostrou uma desidratação média das estacas de $6,72 \%, 13,41 \%$ e $14,17 \%$, respectivamente para os mesmos períodos.

Para evitar grandes perdas de umidade, o produtor de mudas deve introduzir neste processo certas precauções como o uso de embalagens de plástico especiais, que impeçam a perda de água, mas possibilitem as trocas gasosas, ou pro- porcionar ao ambiente umidade relativa do ar elevada para reduzir essas perdas.

Conforme a Tabela 2, evidenciou-se que a cultivar 'Stallion' é superior para os parâmetros comprimento e número de raízes se comparada com a cultivar 'Toon Hermans', apresentando desempenho superior de $109,1 \%$ e $50,3 \%$, respectivamente. Tais resultados mostram diferenças varietais existentes entre as cultivares e que nem sempre são levadas em conta como fator de qualidade da muda, sendo que estes parâmetros podem influenciar o pegamento e a produtividade da planta.

Tabela 2. Valores médios de comprimento de raízes e número de raízes por estaca avaliado em duas cultivares de crisântemo. Santa Maria, 2009.

Table 2. Mean values of roots length and number of roots evaluated in two cultivars of chrysanthemum. Santa Maria, 2009.

\begin{tabular}{ccc}
\hline Cultivares & Comprimento de raízes $(\mathrm{cm})$ & Número de raízes por estaca \\
\hline Stallion & $27,99 \mathrm{a}$ & $21,15 \mathrm{a}$ \\
Toon Hermans & $13,38 \mathrm{~b}$ & $14,07 \mathrm{~b}$ \\
\hline
\end{tabular}

* Médias da mesma coluna seguida de uma mesma letra não diferem entre si ao nível de 5\% de probabilidade pelo teste de Tukey.

Ao se realizar a análise de regressão, foi possível observar a diferença de comportamento que cada cultivar apresenta frente aos tratamentos (Figura 1). A cultivar 'Stallion' mostra um comportamento curvilíneo, sendo que a melhor resposta quanto ao comprimento de raízes se deu em torno dos 11,4 dias de armazenamento a frio (ponto de máxima da curva) e, após esse período, seu desempenho decresceu. Já a cultivar 'Toon Hermans' revela um comportamento linear decrescente quanto à resposta ao comprimento de raízes, sendo que, com o passar do tempo de armazenamento a frio, o desempenho piorou os índices de crescimento radicular (Figura 1-A).

Quanto ao número de raízes por estaca (Figura 1 - B), a melhor resposta para a cultivar 'Stallion' foi semelhante a encontrada para o comprimento de raízes, sendo que o ponto de máxima para esta equação foi de 11,7 dias. Entretanto, para a cultivar 'Toon Hermans' houve um efeito negativo do frio sobre este parâmetro, demonstrado que nem todas as cultivares de crisântemo tem as baixas temperaturas como um componente de produção favorável à melhoria da qualidade da muda.

Apesar da cultivar 'Stallion' apresentar uma forte desidratação aos 21 dias de estocagem a frio (22,2\%), verifica-se que o efeito do frio sobre os parâmetros analisados foi sempre superior às estacas sem tratamento de frio, como observado por HARTMANN et al. (1997), que constataram que o armazenamento de crisântemo por 12 dias, a uma temperatura de $10^{\circ} \mathrm{C}$, incrementa o enraizamento de estacas se comparadas àquelas não armazenadas. SAKAMOTO (2005), ao avaliar os efeitos da refrigeração sobre estacas de cordiline (Cordyline rubra Hügel) também observou que aquelas armazenadas em ambiente refrigerado apresentam melhores resultados quanto ao seu posterior desenvolvimento se comparadas com as estocadas à temperatura ambiente.

Tal comportamento evidenciou que a cultivar 'Stallion' tem um potencial para ser armazenada por um maior período sob baixa temperatura. Já o comportamento da cultivar 'Toon Hermans' demonstrou o inverso.

$\mathrm{O}$ estresse hídrico causa nas folhas um fechamento estomatal, no entanto, este é um efeito secundário à resposta da síntese de ácido abscísico, que atua nas células guarda dos estômatos, acelerando o seu fechamento. Especificamente, quando as estacas de crisântemo são armazenadas por períodos mais longos do que 14 dias, e em função do nível de desidratação que ocorre, o ácido abscísico sintetizado pelas folhas e potencializado pela ação do etileno (TAIZ e ZEIGER, 2004), tem sua ação manifestada assim que as mudas são colocadas para enraizar. Consequentemente, ocorre a senescência, isto é, o amarelecimento principalmente das folhas inferiores das estacas, e com graves danos na formação de raízes, além de provocar a infestação de fungos decompositores das mesmas.

\section{CONCLUSÃO}

O efeito do frio se mostra favorável ao enraizamento de estacas de crisântemo, no entanto, este pode ter efeito deletério conforme a cultivar e o tempo de armazenamento.

O nível de desidratação dos tecidos das estacas de crisântemo parece ser um elemento que causa efeitos secundários responsáveis pelas dificuldades na formação de raízes.

A capacidade de formação de raízes pelas estacas de crisântemo é um caráter varietal, o que se evidenciou na fraca formação de raízes pela cultivar 'Toon Hermans' quando comparada à cultivar 'Stallion'. 


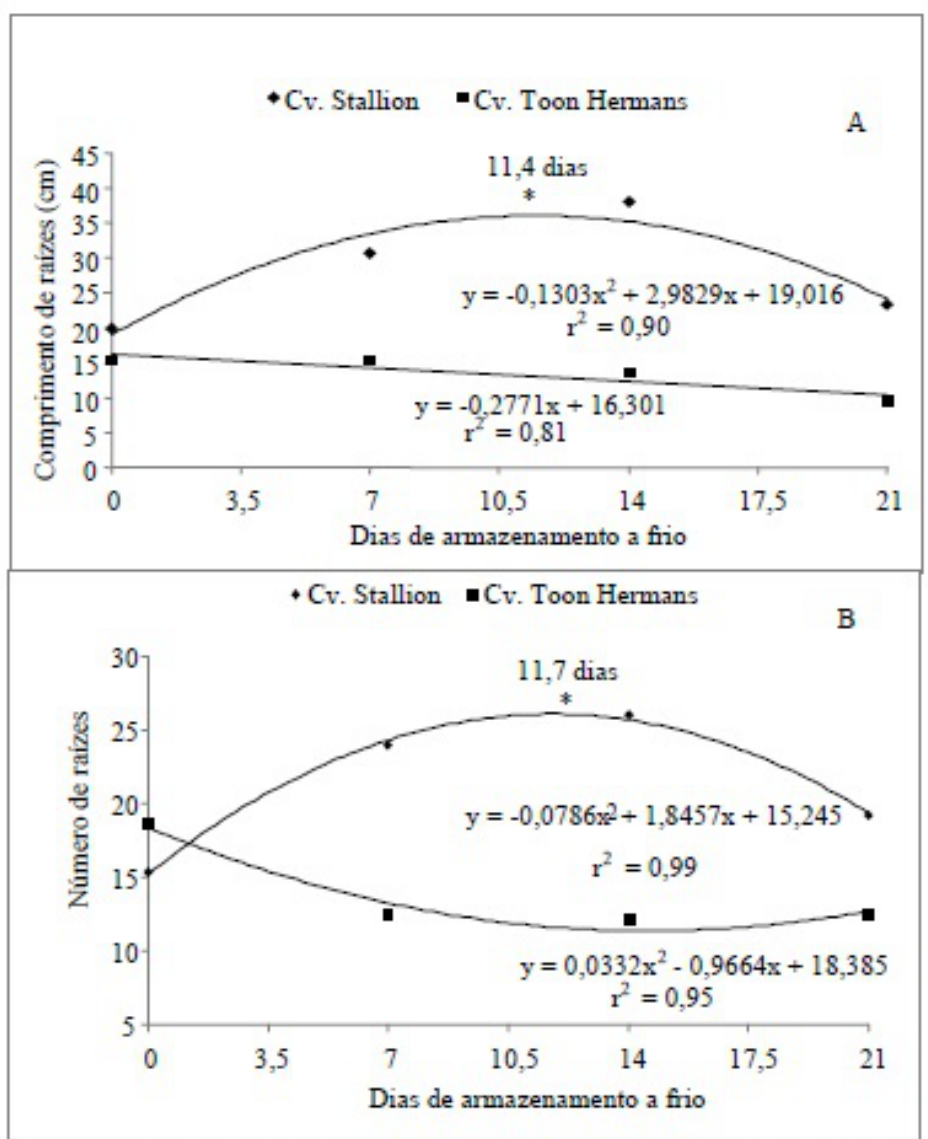

Figura 1. A) Análise de regressão para a interação de dias de armazenamento a frio com cultivares de um experimento bifatorial em delineamento inteiramente casualizado, para a variável comprimento de raizes; B) Análise de regressão para a interação de dias de armazenamento a frio com cultivares de um experimento bifatorial em delineamento inteiramente casualizado, para a variável número de raízes por estaca.

Figure 1. A) Regression analysis for the interaction of cold storage days with cultivars, in a factorial experiment completely randomized design for the variable roots length, B) Regression analysis for the interaction of cold storage days with cultivars, in a factorial experiment completely randomized design for the variable number of roots.

\section{REFERÊNCIAS}

FURLAN, R. A. Consumo de água pela cultura do crisântemo envasado, cultivar 'Puritan', sob condições de estufa. 1996. 65f. (Dissertação Mestrado em Agronomia) - Escola Superior de Agronomia “Luiz de Queiroz", Piracicaba, São Paulo. 1996.

HaRTManN, H. T. et al. Plant Propagation: Principles and Practices. 6 .ed. New Jersey: Prentice Hall, 1997. 770p.

JUNQUEIRA, A. H.; PEETZ, M. S. Crisântemos hoje e sempre: tecnologia de produção. Revista Brasileira de Horticultura Ornamental, v. 26, n. 227, p. 25-27. 2004.

MATSUNAGA, M. Potencial da floricultura brasilei- ra. Agroanalysis, v. 15, p. 56-57. 1995.

SAKAMOTO, N. M. Sazonalidade, Refrigeração e Diferentes tipos de recobrimento na conservação pós-coIheita de estacas de Cordiline (Cordyline rubra Hügel). 2005. 81f. (Dissertação Mestrado em Agronomia) - Escola Superior de Agricultura "Luiz de Queiroz", Piracicaba, São Paulo. 2005.

TAIZ, L.; ZEIGER, E. Fisiologia Vegetal. 3. ed. Porto Alegre: Artmed, 2004. 719p.

TOLOTTI, J. de C. C. Efeito de redutores de crescimento em crisântemo (Dendranthema grandiflora Tzvelev.) 'Snowdon' cultivado em vaso. 2001. 97f. (Dissertação Mestrado em Agronomia) - Universidade Federal de Santa Maria, Santa Maria, RS. 2001. 